原 著

\title{
若年神経調節性失神患者の圧受容体反射は, コントロール群に此較して高い
}

$\begin{array}{lll}\text { 小貫龍也* } & \text { 小林洋一* } & \text { 箕浦慶乃* } \\ \text { 中川渡辺則和 }\end{array}$

【目的】Head-up tilt test (HUT) で若年者の神経調節性失神 (NMS) 発生時の血行動態 や自律神経活動を明らかにする.【方法】対象は失神既往のある 45 歳以下の 15 例 (男性 9 例, 女性 6 例, 平均年齢 $24.2 \pm 7.1$ 歳)にHUT (80 度, 30 分間) を施行 した. コントロール群として失神既往のない 45 歳以下の 18 例 (男性 14 例, 女性 4 例, 平均年齢 $30.6 \pm 7.2$ 歳) にHUTを施行した. HUT 中の血行動態亡圧受容体 反射 (BRS) を検討した.【結果】HUT陽性の若年 NMS 群は, コントロール群に比 ベ, 起立前臥位で BRS が有意に高く, 起立後早期の全末梢血管抵抗 (TPR) の低下 が認められた. NMS 発症前にBRS は有意に高値となった。【結語】若年 NMS は, コントロール群に比ベBRSの六進, TPR 維持障害が認められ, 血圧低下時に著明 なBRSの上昇から心過動状態に陥りやすい. (心電図, $2007 ； 27 ： 160 １ 66$ )

I.はじめに

神経調節性失神 (Neurally Mediated Syncopy : NMS) は, 器質的疾患のない原因不明の失神のうち, 最も頻度が多いと報告されており, その積極的診断

\begin{tabular}{|ll|}
\hline Keywords & $\bullet$ 神経調節性失神 \\
& $\bullet$ 圧受容体反射 \\
& $\bullet$ 若年者 \\
\hline
\end{tabular}

* 昭和大学病院第 3 内科

（テ 142-8666 東京都品川区旗の台1-5-8）
において Head-up tilt test(HUT)が有用とされてい る ${ }^{1), 2)}$. HUT で誘発されるNMSの発症機序として は血圧, 心拍数の変化のみならず, 血槳カテコラミ ンの上昇や心拍スペクトル解析, 末梢神経のニュー ログラフィーなどの個々のパラメーター検討から自 律神経活動の異常が原因とされている.しかし, NMSは血行動態や自律神経活動, さらには心拍出 量, 末梢血管抵抗などの多因子が複雑に絡み合いな がら引き起こされるため, その病態機序は今なお不明 な点が多( ${ }^{3), 4)}$. また，これらの因子は，年齢によ

Barorecepter reflex sensitivity is higher in young patients with neurally mediated syncope than in control subjects. Tatsuya Onuki, Youichi Kobayashi, Yoshino Minoura, Norikazu Watanabe, Haruyuki Nakagawa, Hiroyuki Itou, Fumito Miyoshi, Mitsuharu Kawamura, Taku Asano, Kaoru Tanno, Takashi Katagiri 
り差を認めるため一律に評価することはできない.

近年，非侵襲的に血圧 $(\mathrm{BP})$ ，心拍数 (HR)，心拍 出量 $(\mathrm{SV})$ ，末梢血管抵抗 (TPR) などの多因子を同 時計測可能なマルチチャンネルレコーダーが開発さ $れ^{5)}$, 不整脈や心疾患の経過観察に有用とされている ${ }^{6}$.

本研究の目的は，このマルチチャンネルレコー ダーを用いて，若年 NMS 患者における HUT 中の血 行動態，自律神経活動を記録し，失神に至る病態機 序を検討することである.

\section{II. 対象と方法}

対象：原因不明の失神または前失神の既往歴があ り 2005 年 3 月から 2006 年 8 月の間にHUTを施行し た若年 15 例 (男性 9 例, 女性 6 例, 平均年齢 $24.2 \pm$ 7.1歳, $11 〜 33$ 歳)である.これらの患者は血液検査, 頭部 CT，心エコー，ホルター心電図などの諸検査 において失神の原因とされる代謝性疾患, 器質的疾 患が否定されていた．また，失神の既往のない，年 齢をマッチさせた健康成人 18 例 (男性 14 例，女性 4 例，平均年齢 $30.6 \pm 7.2$ 歳，22〜 44歳)をコントロー ル群としてHUTを施行した。すべての患者および コントロール群においては，検査前に紙面によるイ ンフォームド・コンセントを得た後HUT 検査を施 行した.

HUT プロトコールと測定方法：HUTは，十分な 安静下で血圧, 心拍数の安定を確認後, 足底板のつ いた tilt台を用い，80度受動起立位で 30 分間施行し た. 低血圧に伴う前失神または失神が出現した場合 にNMSと診断し，その時点でHUTを中止した。 HUT中は, 体表面心電図, 左上腕にマンシェット, 左指に指カフを装着させ，主要な循環動態を同時計 測可能なマルチチャンネルレコーダーTask Force Monitor $^{\circledast}$ (CNSystems MedizintechnikGmbH, Task Force Monitor, model TFM-3040, Austria)を使用 し5), 6), 非侵襲的にsBP, HR, SV, TPRを計測した。

$\mathrm{SBP}$ は連続脈波を使用し指カフから計測され，上 肢に装着したマンシェットで補正したＳVは，イ ンピーダンス法 ${ }^{6)}$ 7)つまり血液と組織のインピーダ
ンスの差を利用し，首と胸に装着した電極から容積 変化を計測し，算出した. HRはサンプリング周波 数 $1,000 \mathrm{~Hz}$ でデジタル記録した四肢 6 誘導の体表面 心電図から求めた。

TPRは, Task Force Monitor ${ }^{\circledR}$ から連続的に計測 された HR，BP，SVから1心拍毎にリアルタイムに 自動計算 $\left(\mathrm{TPR}=\right.$ mean $\left.\mathrm{BP} / \mathrm{HR}^{*} \mathrm{SV}\right)$ した.

圧受容体反射 $(\mathrm{BRS})$ は，シーケンス法 ${ }^{8}$ を使用し， 血圧を横軸， R-R 間隔を縦軸とし， R-R 間隔変動と $\mathrm{sBP}$ 変動が 3 拍連続して上昇した場合の傾きをup$\mathrm{BRS}(\mathrm{msec} / \mathrm{mmHg}), \mathrm{R}-\mathrm{R}$ 間隔変動と $\mathrm{sBP}$ 変動が 3 拍 連続して下降した場合の傾きdown-BRS(msec/mmHg) とした. BRSは心臓迷走神経活動をみており，心臓 迷走神経活動の興奮指標として up-BRS, 抑制指標 として down-BRSとし, それぞれ分けて比較検討した。

\section{解析および統計学的検討}

HR，sBP，SV，TPRは，起立前安静時，起立後 5 分間を 1 分間隔, 終了前 5 分間を 1 分間隔で比較した. BRS は起立位前後 5 分間と起立開始後, 終了前の 1 分間を比較検討した.

測定值は平均值 \pm 標準偏差で表し，両群間の平均 値の比較にはStudent's paired, unpaired-t testを用 い, $\mathrm{p}<0.05$ を有意とした.

\section{III. 結果}

HUTを施行した 15 例中 9 例にNMSが認められ た. 陽性群の平均起立時間は $11.9 \pm 8.2$ 分であり，型 別は血管抑制型 3 例, 心抑制型 2 例, 混合型 4 例で あった。

HUT 単独でNMSが誘発された症例の 9例を NMS 群 (男性 5 例, 平均年齢 $25.6 \pm 7.4$ 歳) とし, コント ロール群 18 例 (男性 14 例, 平均年齢 $30.6 \pm 7.2$ 歳) と 比較検討した（表 1).なお，コントロール群は， HUTで全例陰性であった．コントロール群と NMS 群は年齢に有意差は認められなかった $(30.6 \pm 7.2$ 歳 vs. $25.6 \pm 7.4$ 歳, $\mathrm{p}=\mathrm{NS})$.

\section{1. コントロール群}

起立位になると, 臥位に比べて HR, sBP, TPR 


\section{表 1 患者背景}

\begin{tabular}{|c|c|c|}
\hline & コントロール群 & 若年NMS群 \\
\hline 人数 & 18 & 9 \\
\hline 年齢 & $30.6 \pm 7.2$ & $25.6 \pm 7.4$ \\
\hline 男性 & 14 & 5 \\
\hline 失神回数 (回) & 0 & $5.0 \pm 6.0$ \\
\hline 平均起立時間 (分) & 30 & $11.9 \pm 8.2$ \\
\hline 型別 & - & 3 \\
血管抑制型 & - & 2 \\
心抑制型 & - & 4 \\
混合型 & - &
\end{tabular}

の有意な上昇を認め，SVは有意に低下した（臥位 vs. 起立後1分) (図1).

(1)HR : $72.2 \pm 11.2 / \mathrm{bpm}$ vs. $80.5 \pm 8.6 / \mathrm{bpm}$, $\mathrm{p}<0.001$

(2) $\mathrm{sBP}: 114.0 \pm 12.8 \mathrm{mmHg}$ vs. $128.7 \pm 16.0 \mathrm{mmHg}$, $\mathrm{p}<0.0001$

(3) $\mathrm{SV}: 76.4 \pm 15.8 \mathrm{~mL} /$ beat vs. $60.8 \pm 8.2 \mathrm{~mL} /$ beat, $\mathrm{p}<0.0001$

(4) TPR : $1173.7 \pm 225.0$ dyne $\cdot \mathrm{sec} \cdot \mathrm{cm}^{-5} \mathrm{vs}$. $1613.2 \pm 296.7$ dyne $\cdot \mathrm{sec} \cdot \mathrm{cm}^{-5}, \mathrm{p}<0.0001$

30 分間の HUT 終了前における5分間では TPR, $\mathrm{sBP}, \mathrm{SV}$ に有意変化は認められなかった(図 1，3).

BRSは起立位になると臥位に比べ有意な低下を認 めた (臥位 vs. 起立後1分).

(5)up-BRS : $13.5 \pm 6.5 \mathrm{msec} / \mathrm{mmHg}$ vs. $9.4 \pm$ $6.8 \mathrm{msec} / \mathrm{mmHg}, \mathrm{p}<0.05$

(6)down-BRS : $15.0 \pm 9.3 \mathrm{msec} / \mathrm{mmHg}$ vs. $6.5 \pm$

$2.6 \mathrm{msec} / \mathrm{mmHg}, \mathrm{p}<0.005$

HUT 終了後，臥位に戻ると，再び有意な上昇を 認めた (図2).

つまり，コントロール群では，起立時，静脈還流 量が減少し SVが低下するが, HR 上昇と TPR 上昇 により，血圧が保たれ，そのまま維持された。

\section{NMS 群}

起立位後 $1 \sim 2$ 分までの間は, 臥位に比べ $H R$, TPRの上昇を認め，SVは有意に低下した。しかし，
sBPの有意な上昇は認められなかった（臥位 vs. 起立 後1分) (図1).

(1)HR：67.1 $\pm 12.4 / /$ 分 vs. $76.7 \pm 14.9 / /$ 分, $\mathrm{p}<0.001$

(2) $\mathrm{sBP}: 113.1 \pm 22.7 \mathrm{mmHg}$ vs. $122.4 \pm 29.9 \mathrm{mmHg}$, $\mathrm{p}=\mathrm{NS}$

(3) SV : $81.1 \pm 19.1 \mathrm{~mL} /$ beat vs. $67.4 \pm 13.6 \mathrm{~mL} /$ beat, $\mathrm{p}<0.005$

(4) TPR : $1255.5 \pm 215.2 \mathrm{dyne} \cdot \mathrm{sec} \cdot \mathrm{cm}^{-5} \mathrm{vs}$. $1526.9 \pm 337.3$ dyne $\cdot \mathrm{sec} \cdot \mathrm{cm}^{-5}, \mathrm{p}<0.05$

BRSは起立後 1 分にup-BRS，down-BRS ともに有 意に低下した(臥位 vs. 起立後1分) (図2).

(5)up-BRS : $22.2 \pm 14.4 \mathrm{msec} / \mathrm{mmHg}$ vs. $10.8 \pm$ $5.6 \mathrm{msec} / \mathrm{mmHg}, \mathrm{p}<0.01$

(6) down-BRS : $27.4 \pm 17.1 \mathrm{msec} / \mathrm{mmHg}$ vs. $12.2 \pm$ $6.9 \mathrm{msec} / \mathrm{mmHg}, \mathrm{p}<0.05$

起立位 2 分〜 5分では, TPRが低下, HRの上昇が みられず，それに伴い若干の sBPの低下を認めるも のの，HRの低下は認められず，失神までは至らな かった。失神発作 2 分前はdown-BRS 高值を認め, 発症直前はSVの上昇を認めたが，HR，TPRは低下 し，結果的にsBPの低下によりNMSに至った (図2, 図3).

\section{3. コントロール群 vs NMS 群}

(1)BRS：起立前臥位でBRSは，NMS群がコント ロール群に比べ有意に高かった（up-BRS：22.2 
$\diamond$ 若年NMS群 $\mathrm{n}=9$

フコントロール群 $\mathrm{n}=18$

/ 分

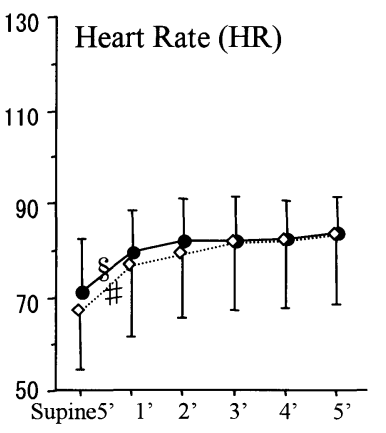

$\mathrm{mL}$

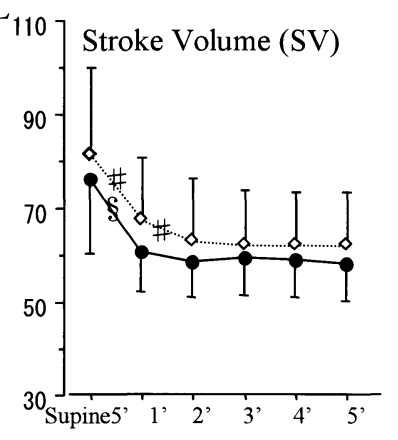

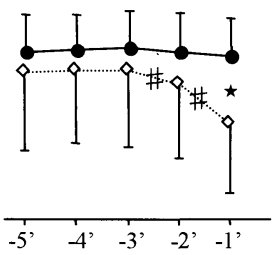

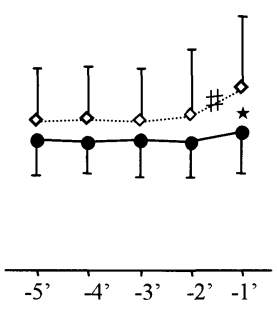

$\mathrm{mmHg} 180$

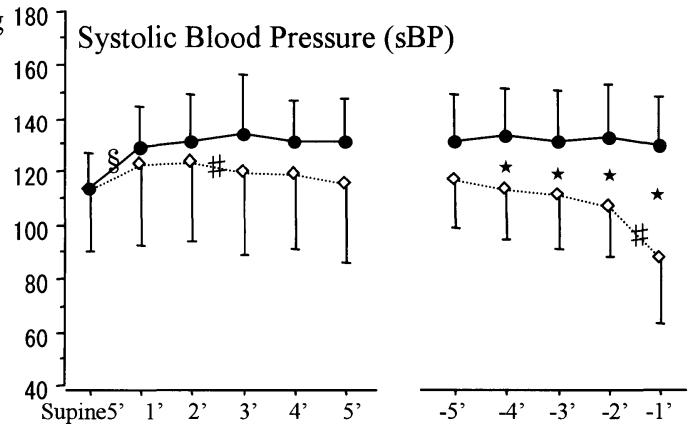

図1 Head-up tilt test中のコントロール群(実線)と NMS 群(点線)の心拍数, 収縮期血圧, 1 回拍出量, 全身末梢 血管抵抗の推移

${ }^{*} \mathrm{p}<0.05$ : 若年 NMS 群の有意変化， ${ }^{8} \mathrm{p}<0.05$ ：コントロール群の有意変化， ${ }^{\star} \mathrm{p}<0.05$ ：若年 NMS群 v.s. コントロール群

$14.4 \mathrm{msec} / \mathrm{mmHg}$ vs. $13.5 \pm 6.5 \mathrm{msec} / \mathrm{mmHg}, \mathrm{p}<$ 0.05) (down-BRS : $27.4 \pm 17.1 \mathrm{msec} / \mathrm{mmHg}$ vs. $15.0 \pm 9.3 \mathrm{msec} / \mathrm{mmHg}, \mathrm{p}<0.05)$. NMS 群は NMS 発症 2 分前から down-BRSの高値を認め，直前にな ると sBP, TPRの低下とともにup-BRS, down-BRS の上昇傾向が出現し, NMSが発症した.

(2)sBP：NMS群は, 終了 4分前からコントロール 群と比べ有意に sBPが低く $(112.6 \pm 18.1 \mathrm{mmHg}$ vs. $133.1 \pm 18.8 \mathrm{mmHg}, \mathrm{p}<0.05), \mathrm{NMS}$ 発症 1 分前で急 速な $\mathrm{sBP}$ 低下を認めた。

(3) TPR : NMS 発症 1 分前でコントロール群に比 べ有意にTPRは低かった（1546.5 \pm 322.0 dyne ・ $\mathrm{sec} \cdot \mathrm{cm}^{-5}$ vs. $1114.9 \pm 420.7$ dyne $\cdot \mathrm{sec} \cdot \mathrm{cm}^{-5}, \mathrm{p}<$ $0.01)$.

(4) SV：NMS群はSVの急激な上昇認め, コント

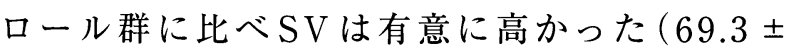
$15.5 \mathrm{~mL}$ vs. $59.8 \pm 8.6 \mathrm{~mL}, \mathrm{p}<0.05)$.

IV. 考察

1. 主な所見

NMS 患者は安静臥位からコントロール群と比べ BRSの高值を認め, NMS 発症2分前より down-BRS が高くなり，発症直前にはSVが増加，ついには心 過動状態が引き起こされ，NMSを発症しているこ とが観察された. down-BRSの高值がNMSの発症の 一因であると思われる。

\section{2. 起立前安静時のBRS 高值}

圧受容体は，大動脈弓部および頸動脈に分布し， 起立時に低下する血圧に反応し，延髄の反射弓によ り HR，TPR上昇をきたし血圧を維持する. 
$\diamond$ 若年NMS群 $\mathrm{n}=9$

○コントロール群 $\mathrm{n}=18$
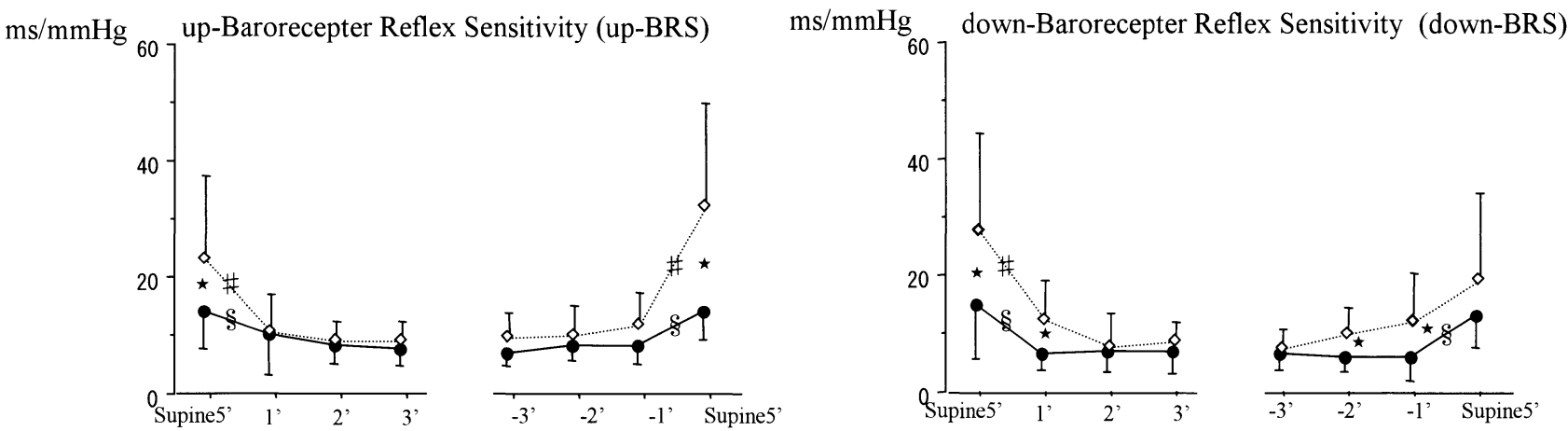

図 2 Head-up tilt test中のコントロール群(実線)と NMS 群(点線)の up-BRS, down-BRS の推移 ${ }^{\#} \mathrm{p}<0.05$ : 若年 NMS 群の有意変化, ${ }^{8} \mathrm{p}<0.05$ : コントロール群の有意変化, ${ }^{\star} \mathrm{p}<0.05$ : 若年 NMS群 v.s. コントロール群
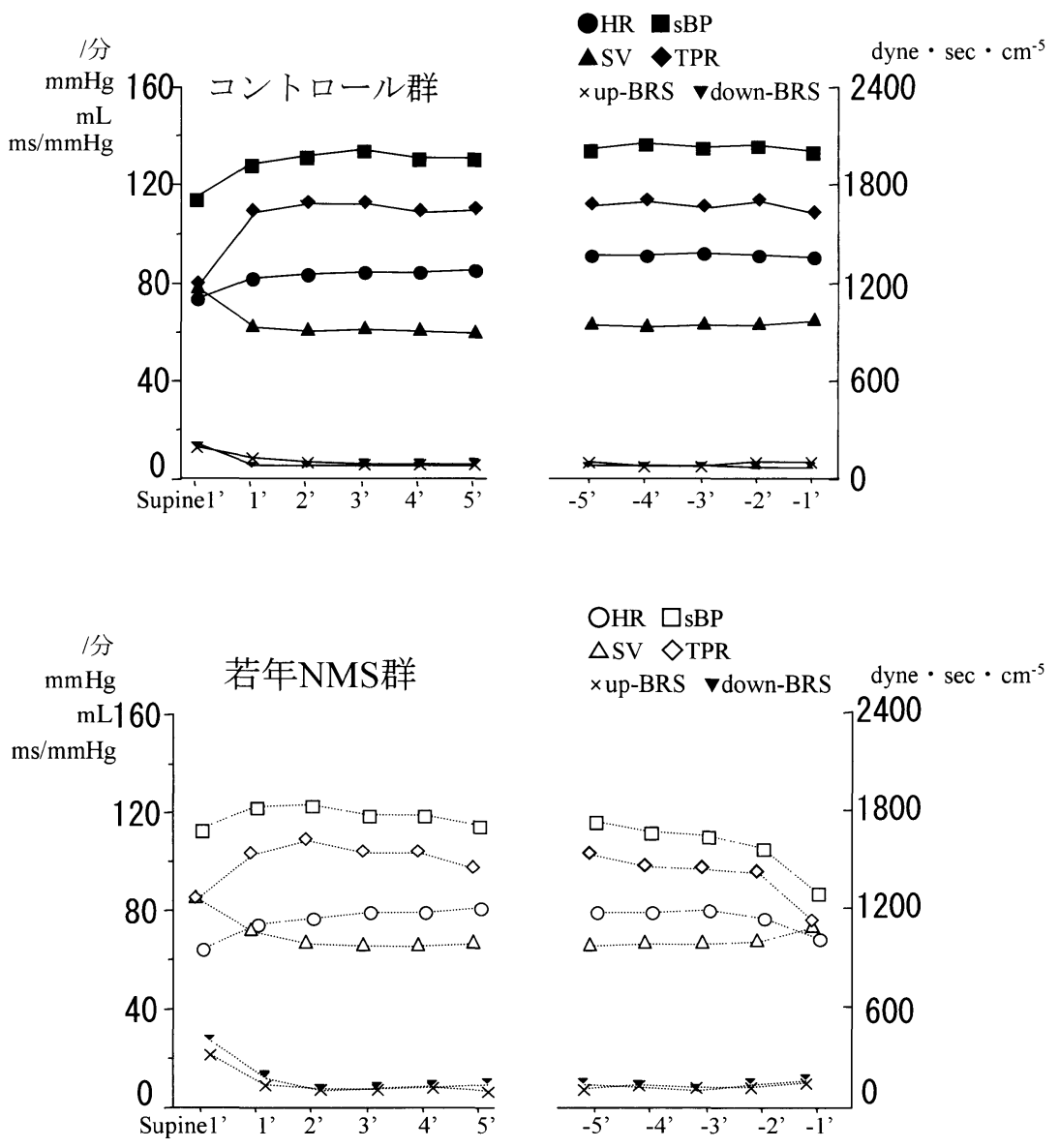

OHR $\square \mathrm{sBP}$ $\triangle \mathrm{SV} \diamond \mathrm{TPR}$ $\times$ up-BRS $\nabla$ down-BRS dyne $\cdot \mathrm{sec} \cdot \mathrm{cm}^{-5}$

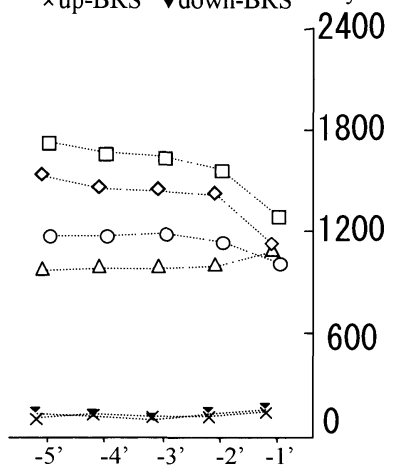

図3 循環動態の推移

上 : Head-up tilt test中のコントロール群(実線)の心拍数(

1 回拍出量 $(\boldsymbol{\Delta})$, 全身末梢血管抵抗 $(\boldsymbol{\nabla})$, up-BRS $(\times)$, down-BRS $(\boldsymbol{\nabla})$ の推移.

下：Head-up tilt test中の若年NMS 群 (点線)の心拍数 $(\bigcirc)$, 収縮期血圧 $(\square), 1$ 回 拍出量 $(\triangle)$, 全身末梢血管抵抗 $(\diamond), \operatorname{up}-\operatorname{BRS}(\times), \operatorname{down}-\operatorname{BRS}(\boldsymbol{\nabla})$ の推移. 
HUTで失神を起こす患者のBRSの変化に異常が あることはいくつか報告されており, NMSの BRS

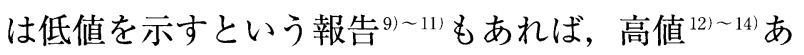
るいは正常 ${ }^{15)}$ であるという報告もある。これは，各 報告で薬物負荷などBRSの測定方法に違いがあるこ とや失神歴の有無, HUTのプロトコールの違い, また，年齢分布にも違いがあるためと考えられる. フェニレフリン負荷などの薬剤負荷による BRS 測定 は, フェニレフリン自体が動脈圧受容器に直接関与 すること ${ }^{16)}$ 17)や，心蔵迷走神経にも影響を及ぼすこ となどが知られており ${ }^{18)}$, BRS変化の結果の相違に 関連しているものと思われる.

Pitzalisらはわれわれと同様にシーケンス法でBRS を求めており, NMS群は安静時のdown-BRSが, 対 照群に比べ有意に高いと報告している ${ }^{13}$ 。この報告 の中でも, 年齢が若く臥位のBRSが高いほど, 立位 早期にNMSを発症している.

われわれの検討では，若年 NMS 患者はコント ロール群に比べて安静臥位でのBRSが高值であり, これにより BRSは血管迷走神経反射に関与している と考えられ, NMS 発症の原因因子の 1 つであると思 われる。

\section{NMS 発症 2 分前からの down-BRSの高值}

NMS 発症前には交感神経活動の指標である $\mathrm{LF} / \mathrm{HF}$ の上昇 ${ }^{4}$ や血漿カテコラミンの上昇 ${ }^{3}$ を認め るという報告がある。この原因として，TPRの維持 障害による血圧の低下と, その結果, 低下した血圧 を維持させようとするdown-BRSの立進があげられる.

われわれの結果は, 発症 2 分前からコントロール 群に比べdown-BRSの高值を認めているため, $\mathrm{LF} / \mathrm{HF}$ 上昇や血漿カテコラミン上昇により $\mathrm{SV}$ も増 加し, ついには心過動状態が引き起こされ, c-fiber の発火により HR, TPRの低下が起こり, NMSが発 症すると考えられる。しかし, 若年 NMS 群では HUT 終了 2 分前から HRの低下があり, 血管迷走神 経反射がBRSの測定に影響した可能性については， 今後の検討が必要である.

\section{4. 発症直前の $S V$ 上昇}

副交感神経遠心路の発火により HR P TPRは急激 に低下するが，NMS 発症直前にSVは上昇したまま であった. カテコラミンから心過動状態を引き起こ す報告 ${ }^{31}$ があり, NMS 発症直前のSV 上昇は心過動 状態を表している可能性がある。

\section{TPRの維持障害}

NMS を発症する患者には根本的に血管収縮反応 の異常 ${ }^{15)}$ がある．われわれの検討でも, NMS 群で起 立後TPR上昇を認めているものの血圧上昇の不良が あり,さらに立位2分から TPR と血圧は低下した。

NMS 症例は, フェニレフリン投与後に対照群に 比べ，血圧の上昇不良や ${ }^{19)}$, HUTで起立から立位後 のTPRの上昇不良も指摘されている ${ }^{201}{ }^{211}$. 本研究 でも, NMS 発症は起立に対するTPR 維持の障害が 考えられた。

\section{6. 結語}

NMS 群はコントロール群に比べ, 起立前臥位で BRSが有意に高く, 起立後には TPRの維持障害を 認め, NMS 発症 2 分前からコントロール群に比ベ BRSの高值を認めた. 結果, BRSの充進とTPRの 維持障害がNMS 発症機序の一つであることが示唆 された。

\section{[文献]}

1) Kappor WN, Karpf M, Wieand S, Peterson JR, Levey GS : A prospective evaluation and follow-up of patients with syncope. N Engl J Med, 1983 ; 309 : $197 \sim 204$

2) Day SC, Cook EF, Funkenstein H, Goldman L : Evaluation and outcome of emergency room patients with transient loss of consciousness. Am J Med, 1982 ; $73: 15 \sim 23$

3 ) Kikushima S, Kobayashi Y, Nakagawa H, Katagiri T : Triggering mechanism for neurally mediated syncope induced by head-up tilt test : role of catecholamines and response to propranolol J Am Coll Cardiol, 1999 ; 33 : $350 \sim 357$

4 ) Nakagawa H, Kobayashi Y, Kikushima S, Kimura M, Obara C, Jinbo Y, Miyata A, Chiyoda K, Tannno K, Kurano K, Baba T, Mukai H, Katagiri T : Important role of autonomic activities developing of neurally mediated 
syncope. Ther Res, $1995 ; 16: 2860 \sim 2867$

5 ) Gratze G, Fortin J, Holler A, Grasenick K, Pfurtscheller G, Wach P, Schonegger J, Kotanko P, Skrabal F : A software package for non-invasive, real-time beat-to-beat monitoring of stroke volume, blood pressure, total peripheral resistance and for assessment of autonomic function. Comput Biol Med, 1998 ; 28 : $121 \sim 142$

6 ) Martin U. Braun, Andreas Schnabel, Thomas Rauwolf, Matthias Schulze, Ruth H. Strasser : Impedance cardiography as a noninvasive technique for atrioventricular interval optimization in cardiac resynchronizati on therapy. Journal of Interventional Cardiac Electrophysiology, $2005 ; 13: 223 \sim 229$

7 ) Van De Water JM, Miller TW, Vogel RL, Mount BE, Dalton ML : Impedance Cardiography : the next vital sign technology? Chest, $2003 ; 123$ : 2028 2033

8 ) Bertinieri G, di Rienzo M, Cavallazzi A, Ferrari AU, Pedotti A, Mancia G : A new approach to analysis of the arterial baroreflex. J Hypertens, 1985 ; 3 : S79 S81

9 ) Morillo CA, Eckberg DL, Ellenbogen KA, Beightol LA, Hoag JB, Tahvanainen KU, Kuusela TA, Diedrich AM : Vagal and sympathetic mechanisms in patients with orthostatic vasovagal syncope. Circulation, 1997 ; 96 : $2509 \sim 2513$

10) Mosqueda-Garcia R, Furlan R, Fernandez-Violante R, Desai T, Snell M, Jarai Z, Ananthram V, Robertson RM, Robertson D : Sympathetic and baroreceptor reflex function in neurally mediated syncope evoked by tilt. J Clin Invest, $1997 ; 99: 2736 \sim 2744$

11) Ellenbogen KA, Morillo CA, Wood MA, Gilligan DM, Eckberg DL, Smith ML : Neural monitoring of vasovagal syncope. Pacing Clin Electrophysiol, 1997 ; 20 : $788 \sim 94$

12) Lagi A, Cipriani M, Fattorini L, Paggetti C, Macerata A : Observations on the arterial baroreflex in neurally mediated vasodepressor syncope. Clin Auton Res, 1994 ;

\section{$4: 307 \sim 309$}

13) Pitzalis M, Parati G, Massari F, Guida P, Di Rienzo M, Rizzon B, Castiglioni P, Iacoviello M, Mastropasqua F, Rizzon P : Enhanced reflex response to baroreceptor deactivation in subjects with tilt-induced syncope. J Am coll cardiol, $2003 ; 41: 1167 \sim 1173$

14) el-Sayed H, Hainsworth R : Relationship between plasma volume, carotid baroreceptor sensitivity and orthostatic tolerance. Clin Sci, $1995 ; 88: 463 \sim 470$

15) Thomson HL, Wright K, Frenneaux M : Baroreflex sensitivity in patients with vasovagal syncope. Circulation, 1997 ; $95: 395 \sim 400$

16) Goldman WF, Saum WR : A direct excitatory action of catecholamines on rat aortic baroreceptors in vitro. Cir Res, $1984 ; 55: 18 \sim 30$

17) Tomomatsu E, Nishi $K$ : Increased activity of carotid sinus baroreceptors by sympathetic stimulation and norepinephrine. Am J Physiol, 1981 ; 240 : H650 H658

18) Pardini BJ, Lund DD, Schmid PG : Contrasting preganglionic and postganglionic effects of phenylephrine on parasympathetic control of heart rate. Am J Physiol, 1991 ; 260 : H118 H122

19) Ono T, Saitoh H, Atarashi H, Hayakawa H : Abnormality of alpha-adrenergic vascular response in patients with neurally mediated syncope. Am J Cardiol, $1998 ; 82: 438 \sim 443$

20) Sneddon JF, Counihan PJ, Bashir Y, Haywood GA, Ward DE, Camm AJ : Impaired immediate vasoconstrictor responses in patients with recurrent neurally mediated syncope. Am J Cardiol, 1993 ; 71 : $72 \sim 76$

21) Shen WK, Low PA, Rea RF, Lohse CM, Hodge DO, Hammill SC : Distinct hemodynamic profiles in patients with vasovagal syncope : a heterogeneous population. JACC, $2000 ; 35: 1470 \sim 1477$ 